\title{
A parametric study of metal-to-metal contact flanges with optimised geometry for safe stress and no-leak conditions
}

\author{
M. Abid*, D. H. Nash ${ }^{\mathrm{a}}$ \\ Faculty of Mechanical Engineering, \\ Ghulam Ishaq Khan Institute of Engineering Sciences and Technology, Topi, Pakistan \\ ${ }^{a}$ Department of Mechanical Engineering, University of Strathclyde, Glasgow, UK.
}

\begin{abstract}
This paper presents the results of a parametric study of the behaviour of metal-to-metal contact flanges that have different surface profiles. Using a finite element analysis approach, the important stress values in the flange and bolts and flange rotation/displacement have been observed for the variation in flange thickness, bolt pre-stress and taper angle (different surface profiles) whilst maintaining other leading flange dimensions (hub length and hub thickness) constant, when vessel/flange component is subjected to internal pressure loading. In addition, results are compared for the flange geometry with no taper angle on flange surface with the predictions obtained from the appropriate sections of the ASME, PD and new European unfired pressure vessel standard EN 13445 Part 3. Based on the results of this study, the best suitable flange dimensions are recommended for no leak conditions from the joint.
\end{abstract}

Keywords: flanges, bolted joints, metal-to-metal, taper angle, finite element analysis, code comparisons, ASME, PD and CEN codes

*Corresponding author

E-mail Address: Fax: 0092-938-71889, abid@giki.edu.pk 


\section{NOTATION}

$A \quad$ outside diameter of the flange

$B \quad$ inside diameter of the flange

C bolt circle diameter

$g_{o} \quad$ wall thickness of basic shell/pipe

$g_{1} \quad$ taper-hub thickness

$h \quad$ taper-hub length

$t \quad$ flange thickness.

ID inside diameter

$P C D$ pitch circle diameter

PT positive taper angle (convex surface profile)

NT negative taper angle (concave surface profile)

NOT no taper angle (flat surface profile)

$\theta \quad$ taper angle on flange surface

\section{INTRODUCTION}

Full-face metal-to-metal bolted flange joints are often used in high integrity situations and also when it is desirable to install a compact arrangement of pipe and flange to minimise space. Although a self-sealing gasket, in the form of an ' $\mathrm{O}$ ' ring, is used to avoid leakage at low pressures, it can, and generally is ignored in the stress analysis of the flange. It is worth noting that although the primary design requirement is to seal the flange connection, there are situations where knowledge of the stresses may be required. To this end, a comprehensive design approach for this component type is given in Appendix Y of ASME Boiler and Pressure Vessel Code, Section VIII, Division 1 [1]. In this, it is suggested that the pre-stress levels in the bolts should be made equal to their operating design stress. The corresponding British Standard, PD 5500:2000 
[2], and the new European Code, EN 13445 [3], provide a less detailed design approach for these flanges, which ignore the influence of the shell. In addition, all such codes do not provide information regarding maximum bolt spacing, minimum flange thickness and exact flange surface profile, namely the taper angle on flange surface for 'no leak' condition. No leak condition in this context means 'zero leak' from the flange joint i.e. mathematically zero displacement at the inside diameter of the mating faces.

A parametric study was performed by Spence et al, [4] for large diameter metal-to-metal nongasketed flanges with variation of hub thickness, flange thickness and hub length without the consideration of the taper angle on the flange surface using finite element analysis (FEA) and analytical approaches from standard design codes. In the present paper, a parametric study of non-gasketed metal-to-metal flange of a size 4" nominal bore, 900\# class is performed for the variation in flange thickness, bolt pre-stress and taper angle whilst keeping hub length and hub thickness constant. The major international codes, ASME, PD5500 and CEN do not apply to these variations in their flange design approach due to the inability to take account of the taper angle on flange surface. Similarly, the results of other studies such as Meck's formula [5] for the maximum bolt spacing for flange sealing cannot be applied to non-gasketed metal-to-metal flanges, due to its limitation of being only applicable to flanges with no taper angle on the main flange mating surface.

The flexibility of the flange is a function of the thickness and the joint height is defined as the combined thickness of both flanges in assembly. The required value of minimum joint height in order to avoid flange rotation or displacement at inside diameter for no leak condition and whilst minimising bolt fatigue due to flange rotation has been determined to be an important factor in this study. This is calculated to be at least six times of the bolt diameter used in the joint and agrees with the statement by Webjorn [6,7], whereas codes as ASME, PD, CEN do not recommend a minimum flange thickness for the no leak condition. In addition, standard design 
codes do not provide any information regarding flange rotation or axial flange displacement at inside diameter.

Lewis et al [8] and Fessler et al [9] performed an experimental study for three different flange joints with positive, negative and zero (no) taper angles on the mating flange surfaces for small sizes and low pressure application flanges made of different materials. They concluded that when a small positive taper angle was machined onto the faces of the flange, then the passage becomes convergent and leakage can be significantly reduced when compared to a similar flange with a small negative taper angle.

\section{AIMS AND SCOPE}

The present work examines the effect noted by Lewis and Fessler using the same finite element model of the earlier study by Nash et al [4]. It this work, the model has changed flange geometry for three different flange surface profiles, six flange thicknesses and four different values of bolt pre-stress. In all cases the maximum values of the longitudinal (axial) bending stress, the radial bending stress and the tangential (circumferential) bending stress, axial flange displacement, flange rotation and bolt stress variation were determined, when subjected to an internal pressure loading regime. The bending stress was isolated in these cases to provide a ready comparison with the bending stress given in the codes. A total of 18 different flange geometries were examined, and four bolt pre-stress values, making a total of 72 different cases. The way, in which the stresses behave, as the flange parameters are varied, have also been determined by both FEA and by the code methods. These predictions are therefore compared and discussed and appropriate results for these studies are presented graphically.

To fully understand the design methodology and influence of the effect of taper angle, the study was divided into following tasks: 
1. To undertake analytical studies for appropriate sections of international codes as ASME Boiler and Pressure Vessel Code, Section VIII, Division 1, Appendix-Y, British Standard, PD 5500, working form 16 and European EN 13445 Code standards for the flange with no taper.

2. To compare the results from FEA model and code calculations for the important stress values for the flange with no taper angle.

3. To perform a full parametric study for the flanges using FEA to;

- examine the effect on flange for the pre-stress applied

- highlight the effect of different flange surface profiles (i.e. taper angles)

- study the effect of minimum flange thickness.

- examine the variation in bolt stress for the bolt up and operating conditions

\section{ALLOWABLE STRESSES AND BOLTED JOINT CONFIGURATION}

The configurations under examination are shown in Figures 1a,b and c. A 4" nominal bore, class 900\# joint is employed throughout this study.

\subsection{Allowable stresses}

The yield stress of the flange and shell material selected was $372 \mathrm{~N} / \mathrm{mm}^{2}$, giving a nominal design stress of the flange material of $248 \mathrm{~N} / \mathrm{mm}^{2}$. An internal pressure of $23 \mathrm{~N} / \mathrm{mm}^{2}$ (230 Bar) was applied which was the proof test pressure for flange size of 4", 900\# class as per codes and was applied for all the cases. For this flange joint, a high strength bolt of $10 \mathrm{~mm}$ diameter as per ISO 898 , grade 8.8 , with minimum yield strength of $640 \mathrm{~N} / \mathrm{mm}^{2}$ was calculated and selected. The minimum bolt stress or operating bolt design stress was taken was $80 \%$ of the minimum yield $[6,10,11]$ i.e. $512 \mathrm{~N} / \mathrm{mm}^{2}$ and was greater than the recommended value by ASME of $372 \mathrm{~N} / \mathrm{mm}^{2}$.

\subsection{Flange geometry}

The dimensional details for flange geometries under consideration are given in Table 1. The 'bolt spacing' requirements round the bolt circle, bolt centre to bolt centre, were set, by the authors, at 
a value of three times the bolt diameter. This was checked using Meck's formula [5] for flange sealing. The number of bolts required and their appropriate diameters, to satisfy the codes, were determined using the procedures set out in the codes for full face, taper-hub flanges. It was found, in general, from code calculations, with the design pressure of $23 \mathrm{~N} / \mathrm{mm}^{2}$, that it was necessary to have 16 bolts of $10 \mathrm{~mm}$ diameter.

\section{FINITE ELEMENT MODELLING}

In the previous papers by Spence et al [12] and Nash et al [4], the viability was established of the approach of using a two-dimensional axisymmetric model, for what is essentially a threedimensional component. In neglecting the holes in the flange, and the presence of individual bolts round the flange, it is assumed that the system can be considered as a simple axisymmetric applied effect. This may be thought of in the form of a continuous bolt ring located at the bolt centre and running round the circumference of the bolt circle. Details of the parameters used in finite element model and a quarter model developed are shown in Figure 2a and Figure $2 \mathrm{~b}$. Throughout the analysis the following material constants were used; Young's modulus, 203,395 $\mathrm{N} / \mathrm{mm}^{2}$ for flange and $204,000 \mathrm{~N} / \mathrm{mm}^{2}$ for bolt and Poisson's ratio, 0.3. The ANSYS, version 5.7, finite element code was employed throughout this work.

\subsection{Element selection, constraints and mesh}

The flange, taper-hub and shell were modelled using the standard two-dimensional (four noded) solid element, 'PLANE42' (ANSYS) with the axi-symmetric option activated. At the contact zones where the two flange metal-to-metal surfaces meet and also at the nut-washer top flange surface, a two-dimensional (three noded) node-to-surface contact element, 'CONTACT48', was employed, this assuming zero friction. The procedure used to handle these elements was similar to that detailed and used earlier [4]. In order to provide a more accurate modelling of the bolts than used previously, where 'BEAM3' elements were employed, the bolts were modelled using 
'PLANE42' elements. Seven of these elements were used across the bolt width, graded to provide a finer mesh at the sides of the bolts; this enabled the distribution of the pre-stress across the width of the bolt to be examined with some accuracy. The layout of the elements is shown in Figure 3, where it is noted that there are seven elements across the vessel and flange thickness.

\subsection{Initial bolt pre-stress loading}

As indicated earlier, the ASME Code in Appendix Y makes the recommendation that a bolt prestress be applied before pressurisation of the component, and that the value of this load be equal to the bolt design stress. The value of this concept has been recognised in previous studies, for example in Webjörn, [6,10,11], and Nash et al [4] and the present lead author [13], in preventing leakage of the joint. In the present studies, the bolt design stress was set at $512 \mathrm{~N} / \mathrm{mm}^{2}$, which is $80 \%$ of the yield of the bolt material. In order to examine the influence of the pre-stress four values of the initial bolt stress were applied, viz., $382,472,512$ and $640 \mathrm{~N} / \mathrm{mm}^{2}$, which are $60 \%$, $70 \%, 80 \%$ and $100 \%$ of the yield of the bolt material. The effect of initial pre-stress on either side of bolt design stress is applied to study its effect on stresses in flange and bolts in addition to joint opening. The procedure for achieving these initial stress values in the FEA was by assigning certain displacement values to the lower bolt surface, which were optimised, until the required pre-stress was achieved.

\section{CODE PREDICTIONS}

In the case of the ASME, Appendix Y, the bending stress values in the three directions, longitudinal, radial and tangential, can be determined directly using the comprehensive analytical approach. The equation for the maximum longitudinal hub bending stress, given in the code, does not indicate the location of this stress, but rather only the magnitude. In the case of the radial flange bending stress, this can either be determined at the bolt circle or at the inside diameter. It was found that the radial bending stresses at the bolt circle were always greater and therefore, 
these are plotted. The tangential flange bending stress was determined from Appendix Y procedure, at the inside diameter of the flange and so is compared directly with the FEA predictions.

In the case of the PD 5500:2000, for the metal-to-metal full faced flange, the equation given is cast in the form which enables the flange thickness to be determined from the allowable stress. In essence the equation arises from a 'ring bending' analysis. It thus assumes that the maximum stress is the radial bending stress in the flange and limits this stress to the allowable stress. The approach does not consider the influence, or the existence, of the taper-hub, nor does it enable the longitudinal stress to be determined. The treatment assumes that the applied bending can be obtained in a 'statically determinate' manner from the applied forces. Of course, the longitudinal stress in the hub could be determined outwith the code, using a cylinder 'edge bending' calculation. This is discussed later.

For the full faced metal-to-metal flanges, the new European pressure vessel code, follows exactly the same approach as is contained in the PD 5500. Since these only provide radial bending stresses the comparisons with the FEA results for the PD and European codes, are restricted to these values.

\section{PARAMETRIC STUDIES}

\subsection{Studies 1 and 2 - Variations in flange stresses under different pre-stress Maximum bending stress in the flange}

Both the FEA and calculations (using the ASME Appendix-Y, PD5500 working form 16 and new European code) were performed and compared for the following two flange geometry conditions as;

1. satisfying all the requirements for the codes regarding bolt spacing, clearance from the edge and hub as well as the allowable stresses 
2. using the original dimensions of the flange used in the experimental work [13] but ignoring the taper angle on flange surface.

Results for the longitudinal hub, radial and tangential bending stresses from FEA are compared with the results obtained from ASME, PD/CEN code and are recorded in Table 2. In the case of the longitudinal bending stresses, the maximum occurred at the hub flange intersection i.e. large end of the taper-hub. The maximum radial bending stress occurred at the bolt circle diameter, and the maximum tangential bending stress occurred at the inside surface of the flange. These three stress values, obtained from the FEA, are plotted in Figure 4 for the four pre-stress bolt values of 382, 427, 512 and $640 \mathrm{~N} / \mathrm{mm}^{2}$. These are denoted as PS-382, PS-427, PS-512 and PS-640 respectively, on the legend.

\subsection{Study 3 - Variation in flange stress, rotation and displacement under different pre- stress}

\section{Maximum bending stress results}

In all, a total number of 72 cases, for 18 different flange geometries, have been studied. The influence of the flange thickness and angles on the flange surface on flange and bolt stresses are plotted and discussed. As with Studies 1 and 2, the same stress behaviour in flange, namely longitudinal hub, radial and tangential bending, were observed. The three stress values, obtained from the FEA, are plotted for the four pre-stress bolt values of 382, 427, 512 and $640 \mathrm{~N} / \mathrm{mm}^{2}$ with positive, negative and no taper angles are plotted in Figures 5a, 5b and 5c respectively. These are denoted PS-382, PS-427, PS-512 and PS-640 respectively, on the appropriate legends.

\section{Flange Rotation and displacement}

In an effort to quantify the possibility of leakage from such a flange, the longitudinal displacements at the inside surface, that is the opening of the flange faces on one side, are plotted in Figure 6. The results are for the flange with dimensions; thickness =10, 15, 20, 25, 30 and 35 mm, taper angle $=0^{\circ},+0.03^{\circ},-0.03^{\circ}$ with applied internal pressure of $23 \mathrm{~N} / \mathrm{mm}^{2}$ and four cases 
of bolt pre-stress. Results of minimum flange thickness calculated (15 mm) using ASME, PD, CEN codes and the minimum thickness recommended using FEA $(30 \mathrm{~mm})$ in this present study for flange displacement at inside diameter with different flange surface profiles are recorded in Table 3. A comparison of maximum axial flange displacement at the inside diameter (from FEA) for flange with positive, negative and no taper angles and various pre-stress applied for the minimum flange thickness calculated by codes and FEA are also plotted in Figure 7.

\subsection{Study 4 - Variation in bolt stresses under different pre-stress Bolt stress and bolt bending}

The displaced shape, of a bolt, when subject to the operating condition i.e. internal pressure load, is shown in Figure 8. The effect of initial bolt pre-stress on bolt stress variation during operation and the bolt bending during pre-stress and pressure loading was noted at the inside and outside node of the bolts. For all 72 cases, for the 18 different flange geometries, bolt-bending behaviour is plotted in Figures 9a, 9b and 9c during bolt up and operating conditions. In addition, the effect of initial pre-stress applied to the bolt is also discussed in order to control the bolt bending to avoid fatigue in the bolt and the joint.

\section{DISCUSSION OF RESULTS}

\subsection{Studies 1 and 2 - Flange stress behaviour}

With direct reference to Table 2, the following may be concluded. The ASME code provides predictions both for longitudinal and radial stresses, whereas $\mathrm{PD} / \mathrm{CEN}$ provides only for radial stresses at PCD.

1. Longitudinal stress: ASME and FEA predictions show almost the same stress results.

2. Radial stress: At the inside diameter, stresses are found slightly higher than the FEA predictions. The ASME and the PD5500/CEN results are conservative when compared with 
the predictions from the FEA at the bolt circle diameter (PCD). However, results from PD5500/CEN are found higher than the ASME predictions.

3. Tangential stress: The ASME results are unconservative when compared with the predictions from the FEA.

4. Effect of bolt pre-stress: The magnitude of the longitudinal and tangential bending stress is almost independent of the pre-stress (see Figure 4); however a negligible small increase in radial bending stress observed with the increase in bolt stress.

\subsection{Study 3 - Flange stress, displacement and rotation behaviour}

\section{Longitudinal hub bending stress}

The longitudinal hub stress decreases with an increase in flange thickness for all three types of taper angles and became constant at the flange thickness of $25 \mathrm{~mm}$ (Figure 5a). For flange thicknesses up to $20 \mathrm{~mm}$, the longitudinal stress is almost independent of the pre-stress applied in the bolts. The highest stress pattern was observed for the positive taper angle profile, whereas the lowest stress pattern was observed for the negative taper angle.

\section{Flange radial stress at PCD}

The radial flange bending stress decreased almost to zero with the increase in flange thickness with positive taper angle (Figure 5b). It became constant for the positive taper angle for flange thickness of $25 \mathrm{~mm}$ and above. For an increased pre-stress, the radial stress decreased for all the three flange surface profiles. The maximum radial bending stress at the bolt circle diameter increased for the flange with negative taper angle and decreased with the increase in flange thickness. The same pattern was observed for 'no taper angle' however the magnitude of the resulting stresses was lower than those of the negative tapered angle flange.

\section{Flange tangential stress}

For flanges $25 \mathrm{~mm}$ and smaller, the stress is independent of the pre-stress applied but for the thicker flanges it increased with an increase in pre-stress (Figure 5c). For the negative and no 
taper angle cases, the tangential stress decreased with an increase in flange thickness and applied pre-stress whereas, higher stresses were found with the positive taper angle case.

\section{Flange displacement and rotation}

The maximum flange opening or displacement at inside diameter or flange rotation is obvious for the flange with negative taper angle even at higher flange thickness (Figure 6). It is noted that for the flange of 35-mm thickness with negative taper angle the flange displacement at the inside diameter for the same pressure loading and pre-stress applied is greater than the flange of thickness $10-\mathrm{mm}$ with positive taper angle. Similarly, for the flange with no taper angle for the same loading and pre-stress applied conditions, flange displacements /rotation of the thickest flange is about $10 \%$ higher. For both types of flanges with negative and no taper angles, the flange displacement reduced with an increase in pre-stress. For the flange with positive taper angle, flange displacement/rotation is almost in linear relationship with the flange thickness and reduced to almost zero for a flange thickness of $30 \mathrm{~mm}$ and above for all the pre-stress conditions.

\section{Comparison of flange designed using codes and FEA}

With reference to Table 3 and Figure 7, the following may be concluded. From Table 3, for the flange thickness of $30 \mathrm{~mm}$ with positive taper angle, a very small flange displacement of 0.0005 to $0.0007 \mathrm{~mm}$ is almost independent of the pre-stress applied from $60 \%$ to $100 \%$ of the yield of the bolt. However, it varied from 25-40 times higher for a negative taper angle and was 14-16 times higher for the flange with no taper angle for the same pre-stress. From this it can be concluded that a good contact at the inside diameter with negligible small initial gap can only be obtained using positive taper angle at the flange surface.

Rotation for flange with zero taper angles is almost double and for negative taper angle is almost 3.5 to 4 times compared to that of the flange with positive taper angle. Comparing, the displacement of flange by codes $(15 \mathrm{~mm})$ is about 15 times more than the FEA recommended flange thickness $(30 \mathrm{~mm})$. 


\subsection{Study 4 - Bolt stress behaviour}

With reference to Figure $9 \mathrm{a}, 9 \mathrm{~b}$ and $9 \mathrm{c}$ at inside node the difference in bolt stress is greater for the flange with negative taper angle. This difference was less for the thicker flanges. This is attributed to the flange rotation under both the bolt up and operating conditions. Even at a prestress of $100 \%$ of the yield of the bolt, a difference was noted at the inside and outside node. For the flange with no taper angle, the difference noted was small at higher pre-stress values but still for the flange thickness of $35 \mathrm{~mm}$ the difference is obvious. For the flange with positive taper angle, the difference was noted only for the flange of $10 \mathrm{~mm}$ thickness. For the thicker flanges it was almost zero, especially at the inside node again due to little or no flange rotation.

\section{DISCUSSION AND CONCLUSIONS}

A comprehensive parametric study has been undertaken for a series of non-gasketed metal-tometal bolted flanged joints for a variety of taper angles and loading conditions. Comparisons have also been made between a numerical approach and standard code calculation methods.

From the stress results, the highest stress is always at the hub-flange intersection and it increases with an increase in pre-stress. This is in contradiction to the flange design analysis in the study by Nash et al [4], where the highest stress was at hub-pipe intersection. It is concluded that this is due to the better parametric selection i.e. instead of sharp taper hub geometry, an elliptical portion is introduced between hub and flange intersection. In addition, this flange design with original dimensions and no taper angle provides a better control for the flange bending stresses.

Overall, the stress results calculated from FEA and codes are within the allowable stress limits up to the proof test pressure (i.e. $20 \sim 40 \%$ of the yield of the flange material).

With knowledge of the flange stress behaviour, a limit analysis may thereafter be performed to achieve a better joint load capacity. The same flange can be used for higher pressure ranges, as this flange has behaved well up to the proof test pressure and the stresses noted were significantly lower than the allowable stress limits. Knowing the stress pattern within the allowable stress 
range for the flange at operating conditions, it is important to avoid the flange displacement/rotation at the inside diameter and so proper contact at the inside diameter is essential. To achieve a static condition in the joint, which has been proved present for the flange with positive taper angle case, the need is to determine the minimum required flange thickness, as thickness calculated using codes do not guarantee for no-leak condition due to flange displacement. It is recalled that the codes do not provide any information other than for flat flange surface profiles.

Bolt fatigue strength for the flange with positive taper angle is concluded to be the highest and fatigue strength is lowest for the flange with negative taper angle, where a dynamic condition (due to bolt bending) is present during the operation. This will ultimately lead to joint failure. The importance of a machining the exact flange profile, ensuring accurate dimensional parameters and the monitoring the applied pre-stress in the joint for the static loading mode in the joint is essential. No information for the bolt pre-stress and bending is mentioned by any of the code or standards available except for the ASME code, which only give a small amount of information regarding the pre-stress to be applied. The bolt pre-stress provides a beneficial stiffness to the flange and reduces the opening of the flange face on the inside surface. In addition, the magnitude of the suitable taper angle on flange surface is also of great importance to avoid the bending of the bolts.

Summarising, for the purposes of design optimisation, a positive taper angle, an elliptical hub, a flange thickness at least six times the bolt diameter, use of high strength bolts of grade 8.8 as per ISO898 or better and with the minimum pre-stress of $80 \%$ of the bolt yield, are recommended.

\section{REFERENCES}

[1] American Society of Mech. Engineers., 'ASME boiler and pressure vessel code, Section VIII, Division 1, App. Y,' 2001 Edition. 
[2] PD5500:2000, 'Unfired fusion welded pressure vessels', British Standards Institution. London.

[3] EN 13445, 'European unfired pressure vessels', CEN, 2002.

[4] Nash D, H., Spence, J., Tooth, A, S., Abid, M., and Power, D, J., 'A parametric study of metal-to-metal full face taper-hub flanges'. Intl. Journal of Pressure Vessel and Piping 2000; (77): pp 791-797, 2000.

[5] Meck, H. R., 'Analysis of bolt spacing for flange sealing'. Journal of Engineering for Industry, Technical Briefs 1969; pp290-292.

[6] Webjörn, J., 'Flange design in Sweden'. Proceedings of the Petrochemical Mechanical Engineering Conference, American Society of Mechanical Engineers. Philadelphia PA: September 17-20, (67-PET-20): 1967.

[7] Webjörn J., and Schneider, R. W., 'Functional test of a vessel with compact flanges in metal-to-metal contact'. Bulletin of the Welding Research Council 1980; (262): pp10-16.

[8] Lewis, L. V., Fessler, H., and Hyde, T. H., 'Determination of the initial gaps between flat flanges without gaskets'. Proceedings of the Institute of Mechanical Engineers 1987; Part A, (201): pp267-277.

[9] Fessler, H., Hyde, T. H., and Lewis, L. V., 'Leakage through loaded flat-flanged joints without gaskets'. Proceedings of the Institute of Mechanical Engineers, Part A, (202): 1988. pp1-13.

[10] Webjörn, J., 'The bolted joint - a series of problems'. Linköping Studies in Science and Technology, Dissertation No. 130 Appendix A: 1985.

[11] Webjörn, J., 'An alternative bolted joint for pipework'. Proc. Instn. Mech. Engrs 1989; (203) Part E; pp135-138.

[12] Spence, J. Macfarlane, D.M., and Tooth, A.S., 'Metal-to-metal full face taper-hub flanges: finite element model evaluation and preliminary plastic analysis results'. Proc. Instn. Mech. Engrs 1998. (212) Part E: pp57-69. 
[13] Abid, M., 'Experimental and analytical studies of conventional (gasketed) and unconventional (non gasketed) flanged pipe joints (with special emphasis on the engineering of 'joint strength' and 'sealing')'. $\mathrm{PhD}$. Thesis, University of Strathclyde, Glasgow, 2000. 


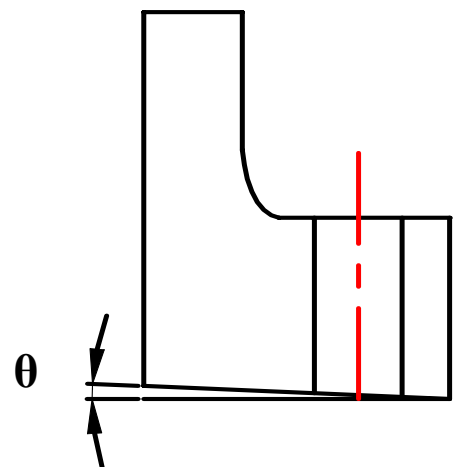

(1a)

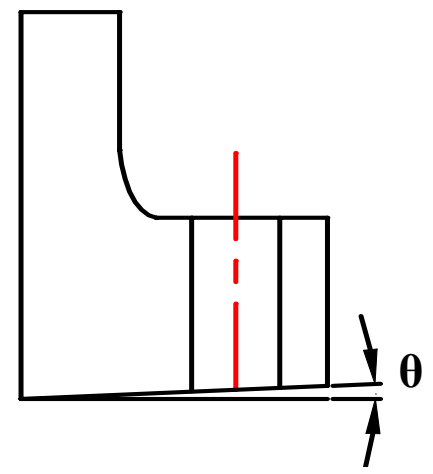

(1b)

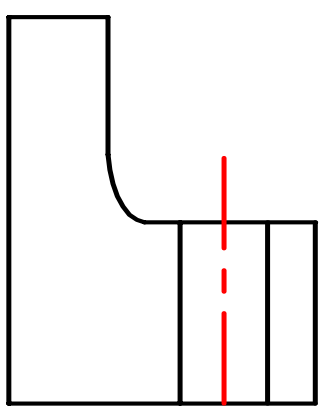

(1c)

Figure 1: Flanges with different surface profiles, (a) Concave Profile or Negative Taper angle, (b) Convex Profile or Positive Taper angle, (c) Flat Surface or without any taper on the Flange Face, Taper angle used during analysis was 0.03 degree.

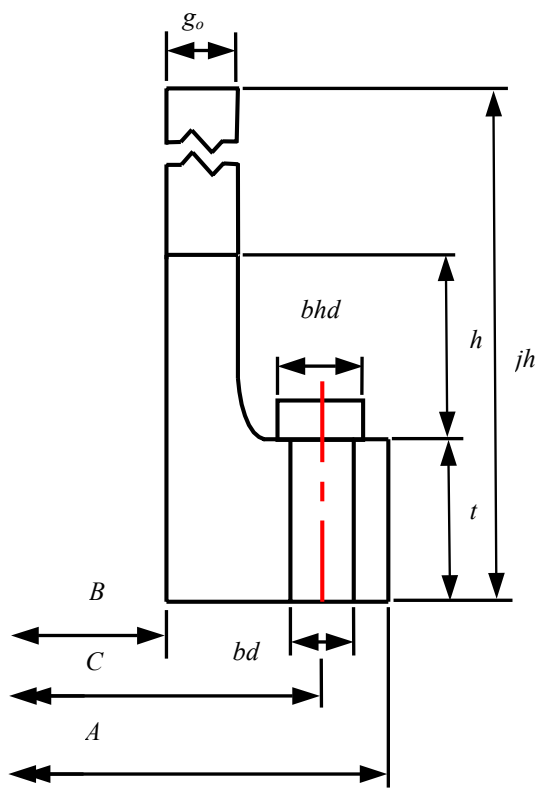

(2a)

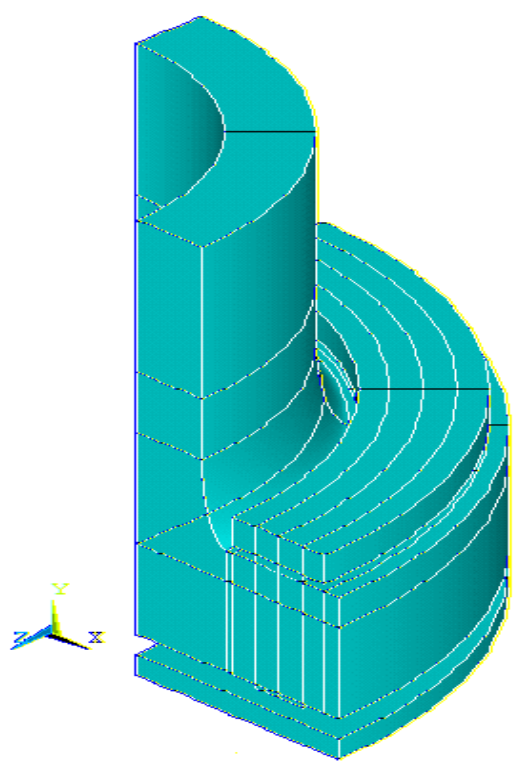

(2b)

Figure 2: (a) Parameters used in the finite element model, (b) Schematic quarter model 


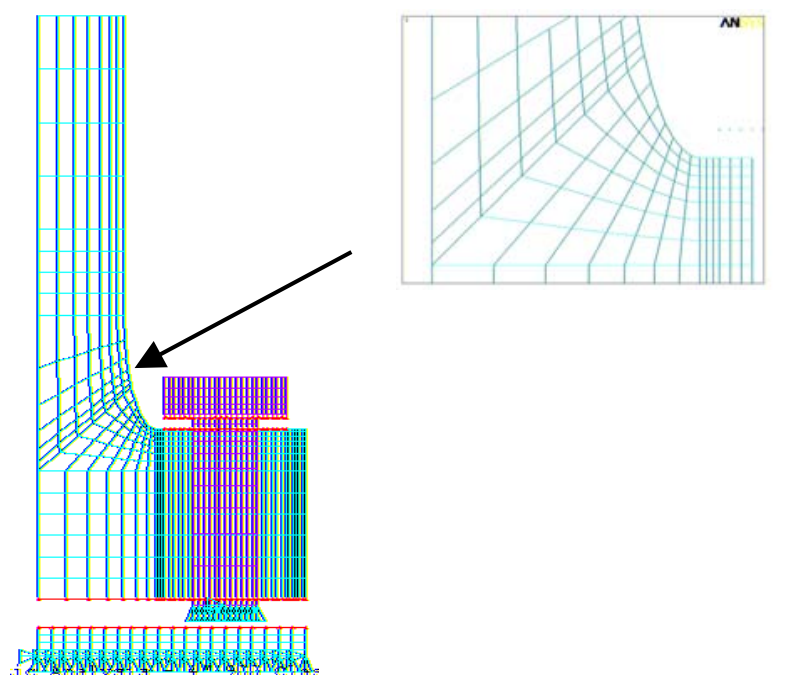

Figure 3: Flange Joint, Element Plot with applied boundary conditions and enlarged hub portion

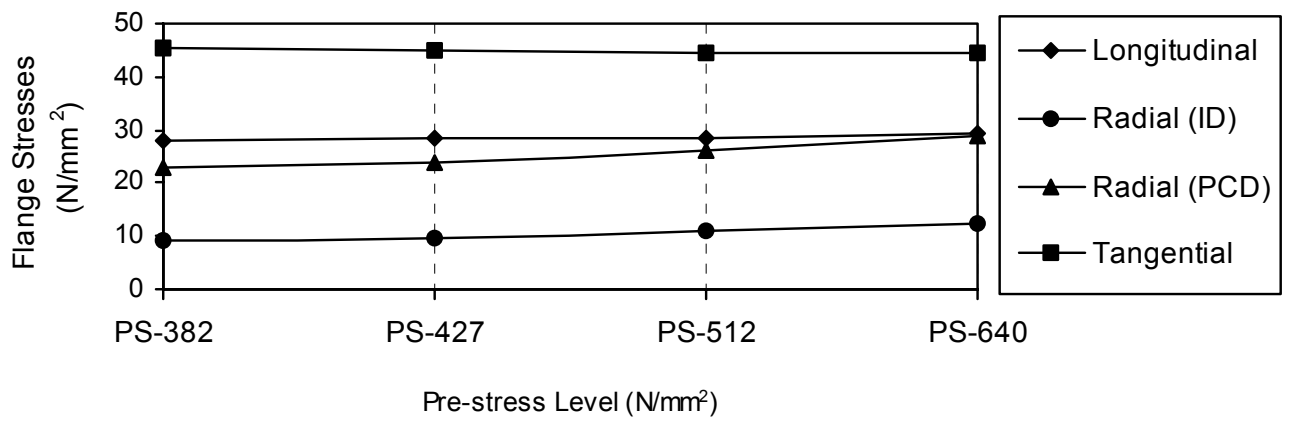

Figure 4: Flange stresses at different pre-stress, (PS-Pre-stress) 


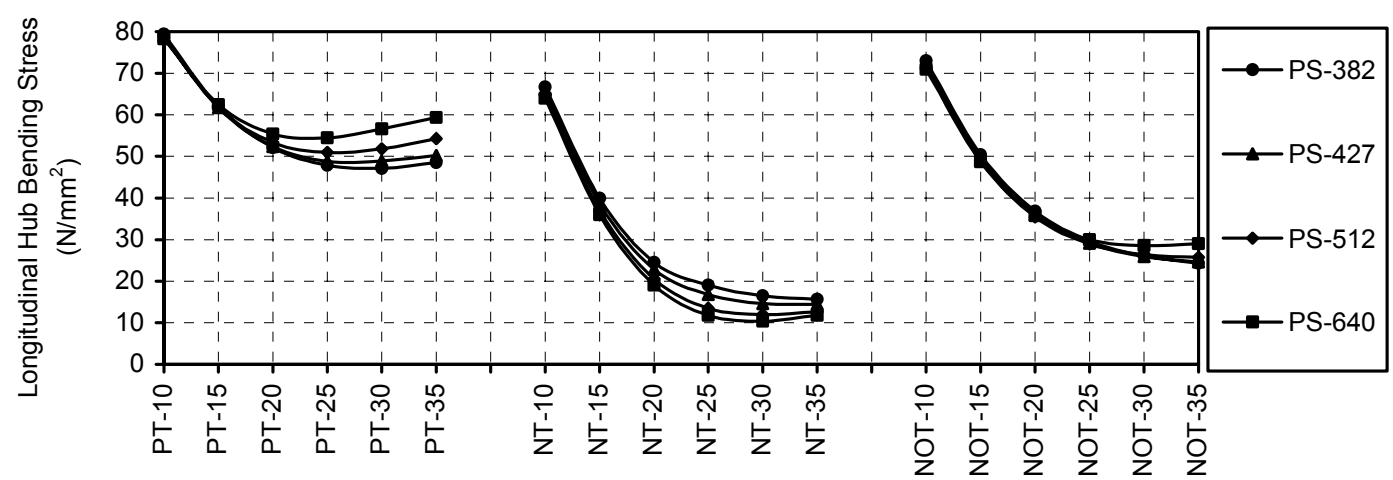

(5a)

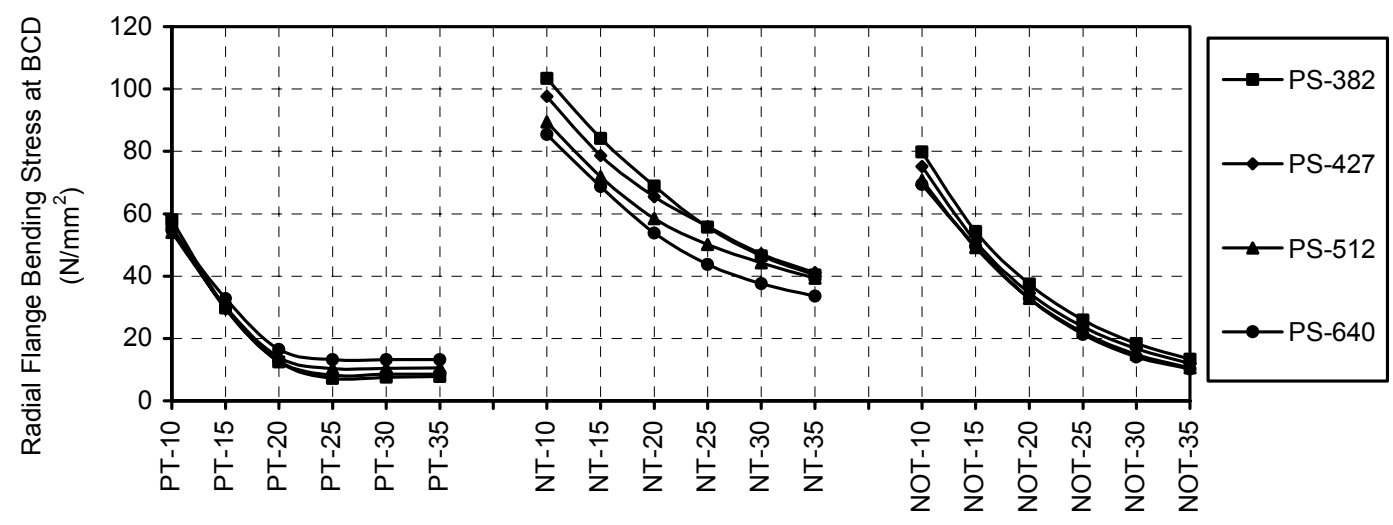

(5b)

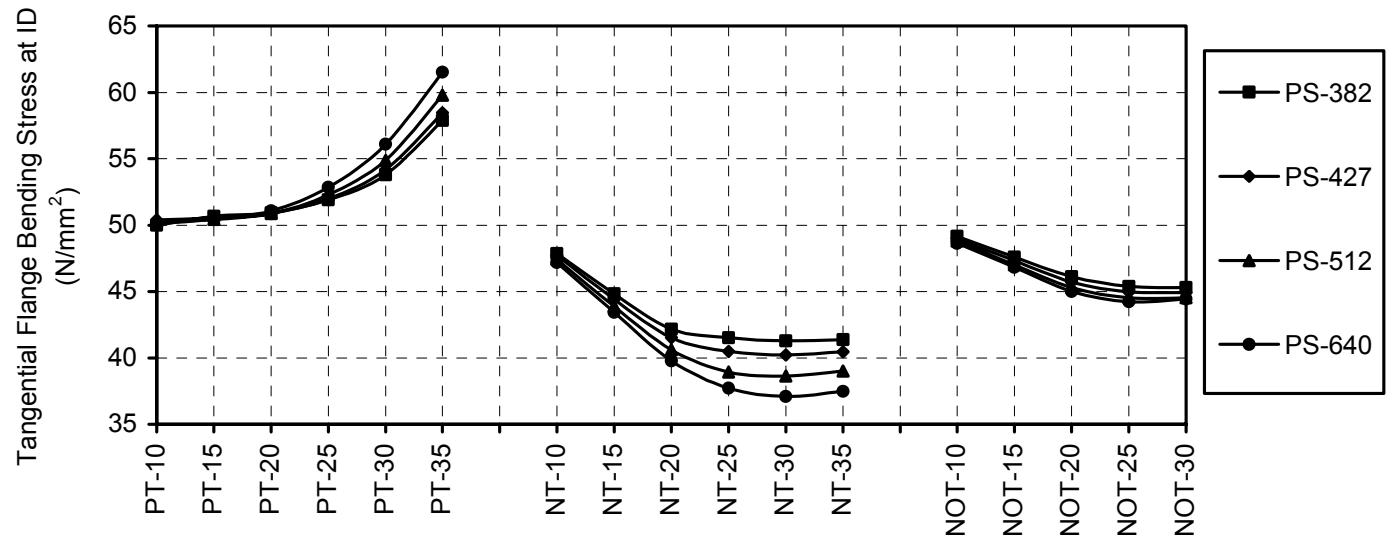

(5c)

Figure 5: Comparison of FEA stress results for Flange with Positive, Negative and No Taper Angles and various Pre-stress applied for a range of flange thickness (10 35 mm) (a) Maximum Longitudinal Hub Bending Stress, (b) Maximum Flange Radial Bending Stress at PCD, (c) Maximum Tangential Bending Stress at ID. 


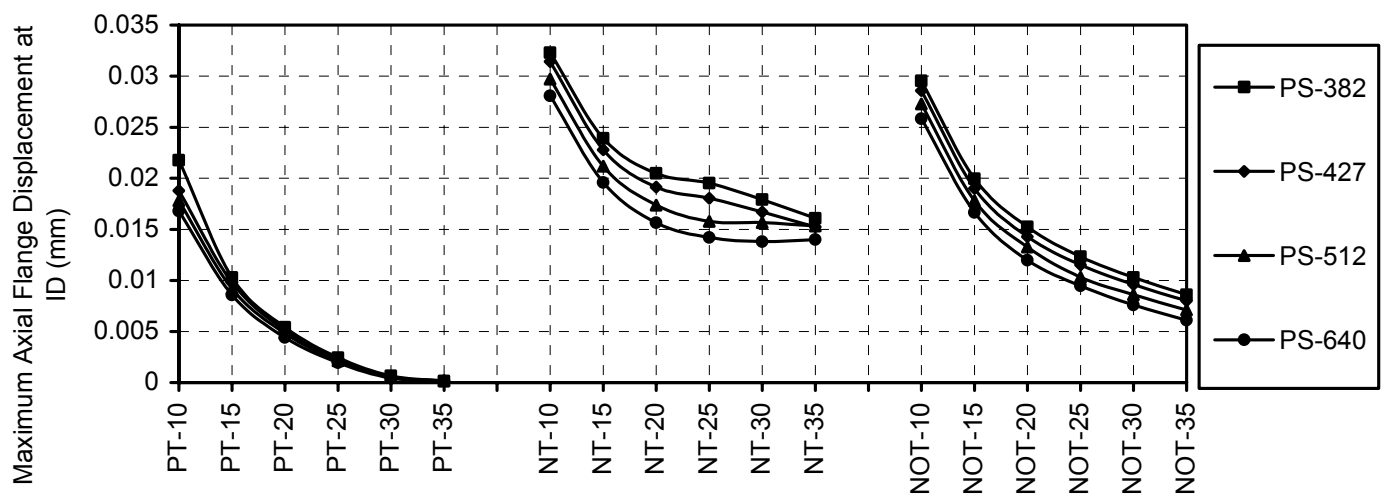

Figure 6: Comparison of Maximum Axial Flange Displacement at ID (from FEA) for Flange with Positive, Negative and No Taper Angles and various Pre-stress applied for a range of flange thickness $(10 \sim 35 \mathrm{~mm})$

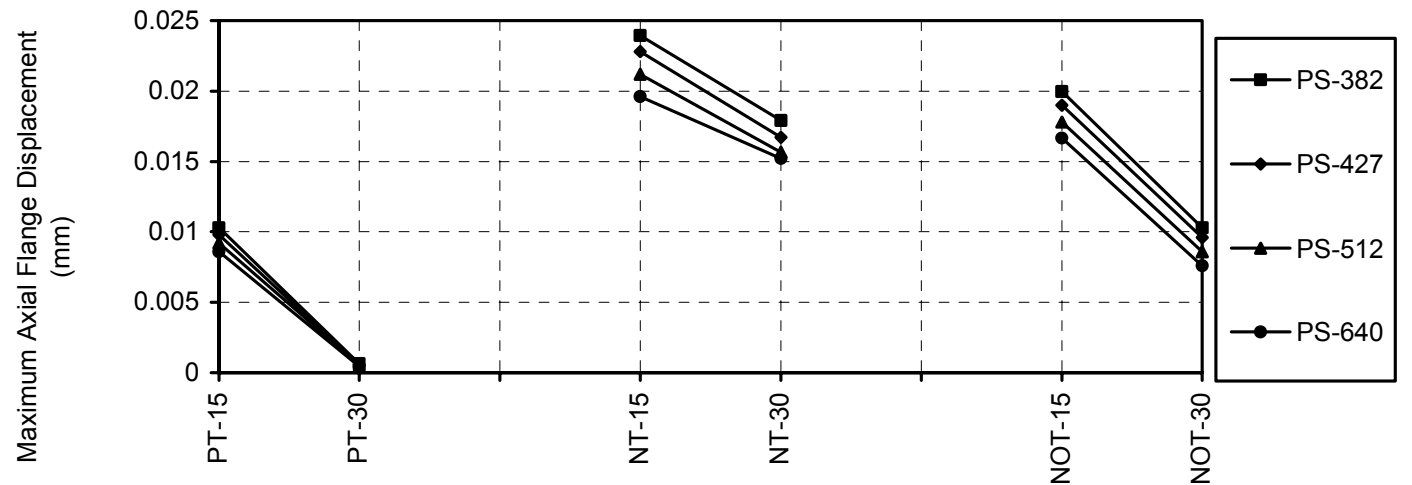

Figure 7: Comparison of Maximum Axial Flange Displacement at ID (from FEA) for Flange with Positive, Negative and No Taper Angles and various Pre-stress applied for the minimum Flange thickness calculated by Codes and FEA



Figure 8: Bolt, Stress Intensity Plot for the full joint due to the operating load 


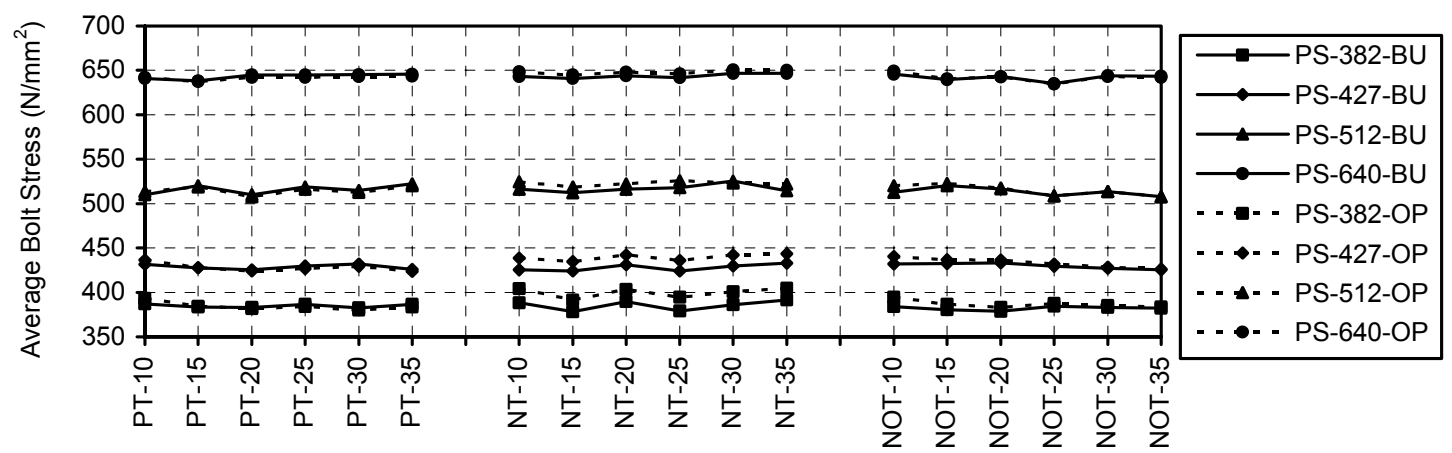

(9a)



(9b)

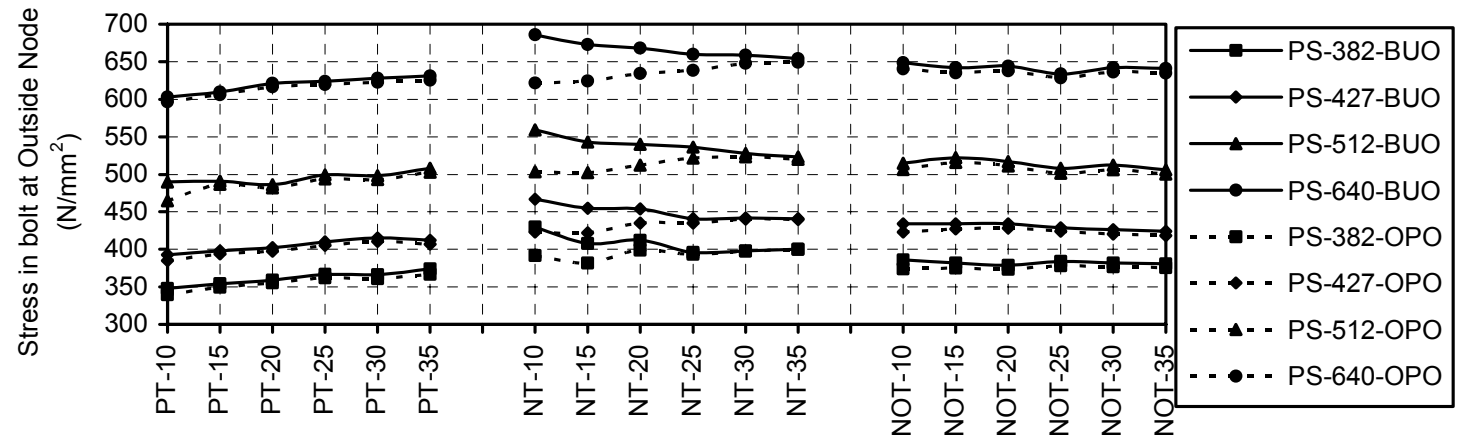

(9c)

Figure 9: Comparison of FEA results during pre-stress \& pressure loading of for Flange with Positive, Negative and No Taper Angles and various Pre-stress applied for a range of flange thickness (10 35 mm) (a) Avg. Bolt Stress, (b) stress in bolt at inside node (b) outside node 
Table 1: Flange geometric parameters $(\mathrm{mm})$

\begin{tabular}{|c|c|c|c|c|c|c|c|}
\hline \multicolumn{7}{|c|}{ Fixed Parameters } & \multicolumn{2}{c|}{ Variable Parameters } \\
\hline $\begin{array}{c}\text { Flange } \\
\text { hub } \\
\text { length }\end{array}$ & $\begin{array}{c}\text { Pipe } \\
\text { thickness }\end{array}$ & $\begin{array}{c}\text { Flange } \\
\text { hub } \\
\text { thickness }\end{array}$ & $\begin{array}{c}\text { Bolt } \\
\text { circle } \\
\text { diameter }\end{array}$ & $\begin{array}{c}\text { Flange } \\
\text { outside } \\
\text { diameter }\end{array}$ & $\begin{array}{c}\text { Flange } \\
\text { inside } \\
\text { diameter }\end{array}$ & $\begin{array}{c}\text { Flange } \\
\text { thickness }\end{array}$ & $\begin{array}{c}\text { Flange surface } \\
\text { taper angle } \\
\text { (degree) }\end{array}$ \\
\hline 34 & 13.5 & 15.5 & 146 & 171 & 87.3 & $\begin{array}{c}10,15,20, \\
25,30,35\end{array}$ & $0,+0.03,-0.03$ \\
\hline
\end{tabular}

Table 2: Flange Stresses as per FEA and Codes

\begin{tabular}{|l|c|c|c|c|c|}
\hline \multicolumn{1}{|c|}{ Stress } & FEA & $\begin{array}{c}\text { ASME } \\
\text { (as per code) }\end{array}$ & $\begin{array}{c}\text { ASME } \\
\text { (Original flange) }\end{array}$ & $\begin{array}{c}\text { PD 5500/CEN } \\
\text { (as per code) }\end{array}$ & $\begin{array}{c}\text { PD 5500/CEN } \\
\text { (Original flange) }\end{array}$ \\
\hline Longitudinal & 28.47 & 36.03 & 29.36 & ---- & ---- \\
\hline Radial (ID) & 11.00 & 18.77 & 15.28 & ---- & ---- \\
\hline Radial (PCD) & 25.96 & 63.13 & 58.05 & 80.75 & 74.37 \\
\hline Tangential & 44.52 & 16.74 & 13.44 & ---- & ---- \\
\hline
\end{tabular}

Table 3: Comparison of Flange Displacement at Inside Diameter (ID) for flanges with positive, negative and no taper angles, using different pre-stress values

\begin{tabular}{|l|c|c|c|c|c|c|}
\hline PS & PT-15 & NT-15 & NOT-15 & PT-30 & NT-30 & NOT-30 \\
\hline 382 & 0.0103 & 0.0239 & 0.0200 & 0.0007 & 0.0179 & 0.0103 \\
\hline 427 & 0.0098 & 0.0228 & 0.0190 & 0.0006 & 0.0167 & 0.0096 \\
\hline 512 & 0.0092 & 0.0212 & 0.0178 & 0.0006 & 0.0157 & 0.0086 \\
\hline 640 & 0.0086 & 0.0196 & 0.0167 & 0.0005 & 0.0162 & 0.0076 \\
\hline
\end{tabular}

